\title{
Tedious: feminized labor in machine-readable cataloging
}

\section{Patrick Keilty}

To cite this article: Patrick Keilty (2017): Tedious: feminized labor in machine-readable cataloging, Feminist Media Studies, DOI: 10.1080/14680777.2017.1308410

To link to this article: http://dx.doi.org/10.1080/14680777.2017.1308410

\section{曲 Published online: 02 Apr 2017.}

Submit your article to this journal $\pi$

Llll Article views: 34

Q View related articles $\widetilde{ }$

View Crossmark data ¿ 


\title{
Tedious: feminized labor in machine-readable cataloging
}

\author{
Patrick Keilty \\ Faculty of Information, University of Toronto, Toronto, Canada
}

\begin{abstract}
This essay examines previously unexplored IBM reports and manuals that document the development of Machine-Readable Cataloging (MARC) in the 1960s to understand gendered assumptions manufacturers made about the labor of information retrieval and to ultimately discuss the ways in which MARC transformed the feminized labor of information, making it more diffuse and shifting expectations about productivity. In the process, this essay will show that cataloging, like other forms of women's labor transformed by technology in the latter part of the twentieth century, has a complicated relationship to the market labor and industrialization. Finally, this essay ends by connecting MARC and feminized labor to the contemporary discussion of BIBFRAME.
\end{abstract}

\section{ARTICLE HISTORY}

Received 8 October 2015

Revised 26 January 2017

Accepted 31 January 2017

\section{KEYWORDS}

Automation; librarians; labor; cataloging; IBM

\section{Introduction}

In 1941, the US government established an Office of Scientific Research and Development to accelerate the war effort. Its director, Vannevar Bush, supervised roughly six thousand scientists, many of whom worried about managing and organizing the rapidly expanding body of scientific and technical information to which they were both contributing and citing. Bush anticipated that the scientific energy generated by wartime efforts would shift to new uses in postwar America. At the end of the war, Bush famously urged scientists to turn to the massive task of making more accessible the "bewildering store of knowledge" (Vannevar Bush 1945, 101). He recognized that newer technologies promised to improve the control of this increasingly large body of literature. His foresight proved accurate. In 1950, the United States Government authorized the establishment of a clearinghouse of scientific and technical information (Wayne A. Wiegand 1999, 15). After the Soviet Union launched Sputnik in 1957, the President's Science Advisory Committee published a report on the availability of scientific and technical information in the United States that left little doubt about why it thought the nation was losing the Space Race. The primary recommendation of the report was to better integrate planning and communication of the federal programs in science and technology (President's Science Advisory Committee 1958, 28).

By the early 1960s, pilot projects were in the works to automate scientific information retrieval, computerize traditional library catalogs, and create a ubiquitous computer-mediated information environment at the National Library of Medicine (MEDLARS), the Library 
of Congress (MARC), and the Massachusetts Institute of Technology (INTREX). These early information retrieval systems, which, as a result of the Space Race, were largely commissioned by the US Air Force as part of a defense-subsidized electronics industry, not only echoed Vannevar Bush's well known "Memex" ideas from twenty years earlier, but also reflected the Cold War military-academic-industrial complex, which Bush helped to inaugurate. ${ }^{1}$ Computers were first designed during World War II to automate calculation, then to control weapons and guide aircraft, and later to analyze problems of command. While women played a crucial role in the early development of computers during World War II (Jennifer Light 1999), Nathan Ensmenger (2010) has shown that computing was swiftly masculinized in the postwar era.

Part of the forgotten history of women in this postwar computing realm is the way automated information retrieval systems, such as MARC, serve as an example of the way in which technological change and information are tied to women's labor and women's bodies. From 1964 to 1969, the Library of Congress developed the format for a standardized machinereadable catalog record, now widely used in libraries throughout the world. ${ }^{2}$ MARC served as an early example of an expert or "thinking" system at a time before the development of early Database Management Systems, which began with the release in 1968 of IBM's Information Management System (IMS), originally designed for NASA's Apollo program. In complicated ways, MARC participates in the commodification of information (Dan Schiller 2007) and a technological history that traces the industrialized market labor of women. This essay will examine MARC within that history, briefly providing the context in which MARC developed, before examining a popular filmic speculation about labor and the automation of information retrieval, and, finally, examining the paradoxical ways in which MARC transformed the feminized labor of information. In addition, it will show that cataloging, like other forms of women's labor transformed by technology in the latter part of the twentieth century, has a complicated relationship to market labor and industrialization.

Social processes such as industrialization, war, and automation created new jobs for which women were considered to be appropriate candidates, including typists, clerks, administrative assistants, nurses, and computer programmers, service jobs we might say provide a significant amount of "information labor." The appropriateness of this work for women was largely based on the assertion that the nature of the work matched presumed feminine skills: attention to detail, endless patience, and repetitive tasks that required limited training or intellectual capacity. These assumptions about the unique nature of women's skills prevailed long before the Second World War. Pre-war feminized professions, such as librarianship, teaching, and social work, had increasingly employed women since the late nineteenth century. By 1920, women composed almost 90 percent of librarianship (Cynthia F. Epstein $1971,7)$. Educated women entered librarianship for a wide variety of reasons: they met resistance in more established male professions; librarianship was a fast growing profession in need of low-paid but educated recruits; and women agreed that library work matched presumed feminine limitations. As Dee Garrison notes, "librarianship was quickly adjusted to fit the narrowly circumscribed sphere of women's activities" $(1979,174)$. The feminization of librarianship (along with teaching and social work), had unexpected long-range results, both on the type of service the library would provide but also in perpetuating the low status of women in society based on presumptions about the natural division of labor that would continue through the postwar years. ${ }^{3}$ 
To various women, at various times, service jobs and the salaries they provided proved to be attractions too great to resist as the war drew to a close and men returned from war to resume their work in the labor force. Some women "continued to work" in the postwar years because they were reluctant to give up the life and the income to which they had become accustomed during the war. Some women found that the growing pressure of inflation was so seriously eroding the purchasing power of their husband's income that they had to go back to work. Other women, as a result of divorce, desertion, or the decision to remain single, in increasing numbers, had no husband's income to fall back upon. Others went home and had babies and did not re-enter the labor force until their children were grown and out of the house. The result was an increase in the number of women in the workforce (Ruth Schwartz Cowan 1983, 202).

\section{Tedious tasks}

An initial corporate report, published by the US Department of Defense contractor Itek Corporation, outlined the goals of developing a "machine interpretable format" for catalogs, stating that the "immediate objective" of these new "machine techniques" is "to lessen the human workload" involved in input processes, and to increase the volume of units which those processes can handle (David E. Sparks 1962, 1). Two years later, a similar report, published by the technical publications department at IBM on behalf of the Data Processing Division, states that the "advantage of mechanized procession of library administrative work" is to eliminate "costly and time-consuming manual effort" (IBM 1963a, 1). Another report cites rising costs and a shortage of professional librarians (IBM 1964b). ${ }^{4}$

To that end, IBM built the IBM 870 Document Writing System, a typewriter and cardpunch combination, and the IBM 1401 Data Processing System, a printer designed to replace the electromechanical unit record equipment for processing data stored on punch cards, another site of feminized labor. The IBM 870 and IBM 1401 were used for coding catalog data into a worksheet, which was then punched into data processing cards (or "punch cards") for input into a computer (IBM 1964a, 9-10). Its report cites an "influx of printed matter," an increase in personnel costs, and the amount of time librarians spend doing "repetitive operations that could be handled by data processing equipment" as reasons for a systems approach to the production of library card data (IBM 1964a, 1).

That same year, the US Air Force commissioned LIBRARY-21, a UNIVAC vision of the "library of tomorrow," designed by Cold War defense consultants working for the Central Intelligence Agency and private industry, which was showcased at the 1962 World's Fair. In anticipation of its debut, The New York Times (1961) described LIBRARY-21 as "an electronic brain capable of dispensing thousands of passages of literature at the touch of a few reference buttons." Its designers imagined automated features that were geographically extensive, where "remote inquiry and automatic catalog search" would "make it possible to answer questions from remote stations-homes, offices, schools, or regional information centers" (Bowles 2000). These remote stations were to be "operable by anyone," designed to be "as foolproof as the telephone" so no specially trained labor would be needed (Downey 2007, 40).

The reports and manuals for these machines, "written for librarians" (Kraft 1966, 1), during the early days of MARC's development were intended to identify the rationale for developing automated information retrieval systems, and to provide technical and descriptive information for doing so. Yet they also reflect computer manufacturers' and designers' assumptions 
about the (feminized) labor these systems would transform, an example of the male bias in the way technology is defined and developed (Judy Wajcman 1991). From its inception, MARC was built to transform labor; and it's reasonable to say that MARC was built to transform labor largely done by women, given the number of women already in the profession. Much of this language assumes cataloging labor requires limited training or intellectual capacity and that it will decrease the labor of cataloging. Numerous reports variously describe the work of cataloging as merely "clerical" (IBM 1968, 31; Kraft 1966, 1), "tedious" (IBM 1968, 8), "unnecessary" (IBM 1963b, 8), "repetitive" (IBM 1963b, 18, 31; 1964, n.p.), "redundant" (1963b, 1 and 31), and "drudgery" (IBM 1960, n.p.). 5 According to these reports and manuals, the clerical and tedious nature of this work (and its presumed lack of intellectual skill) makes it ideally suited for "mechanization" (Sparks 1962, 1), "automation" (IBM 1964a, 1), or a "total systems approach" to card catalogs (IBM 1964b, 1). While several historical studies of information retrieval analyze the rationale behind library automation and its implications for the labor of cataloging (Kenneth Futura 1990; Cheryl LaGuardia 1995; Boyd Rayward 2002), manufactures' and designers' assumptions about that labor has gone previously unexplored. Janet Abbate suggests that previous scholars' "preoccupation with hardware [...] has had the unintended effect of obscuring the role of women" $(2003,4)$. This is because, according to Abbate, "men have been inventors through most of the history of computing" $(2003,4)$. I would briefly extend Abbate's argument, in this case, to suggest that a preoccupation with hardware has likewise obscured assumptions made by manufacturers about women's labor and the potential transformation of computers on that labor.

These assumptions have a well-established history, and they circulated widely in popular culture at the time IBM explored the possibility of automating library catalogs. Postwar literature, television, advertisements, and film abound with representations of the computational transformation of feminized labor. These representations project a range of cultural fantasies, hopes, and anxieties, not just about the increasingly powerful role of computational technology in everyday life, but also, according to Steve F. Anderson, "about the ontological and epistemological status of humans in an increasingly technologized world" (2013, n.p.). This was particularly apparent in feature films and network television, "where mainframe computers-often decommissioned IBM air defense systems-made dozens of appearances" (Anderson 2013, n.p.). These depictions offer a glimpse into the gender, racial, and political dynamics surrounding computer technologies at a time when they moved out of government and military initiatives and into standard business equipment. Meanwhile, according to Abbate (2003), Steve F. Anderson (2011), and Carol Colatrella (2001), manufacturers such as IBM were developing active public relations campaigns to entice women into the technology industries and assuage anxieties about computers in the workplace.

\section{Depicting feminized labor}

The romantic comedy Desk Set (1957), produced with the support of IBM, is perhaps the most popular of these efforts by a manufacturer. According to Mary Flanagan, Desk Set is "the first film depicting an IBM-like 'EMERAC' machine," a homoiophone metonym of ENIAC and UNIVAC, two of the first electronic general-purpose computers $(2004,154)$. Producer Henry Ephron and Director Walter Lang borrowed equipment from IBM to use on the set, an early example of product placement. For its cooperation, IBM received a thankful acknowledgement in the opening credits. According to E. W. Pugh (1995), the company participated 
in the film partly to reassure audiences that computers were non-threatening to the labor force because they were unthinking and suitable only to take over repetitive tasks. Janet Abbate (2012) and Anderson (2013) take this argument further to show that IBM supported the production of the film in order to reassure women in particular that computers were designed to help them, not replace them, and to recruit women to enter computing as a profession. Although fiction, Desk Set attests to the ways in which computers and labor were perceived during the decade when they became open to public view in popular representations and mass media.

In the film, Katherine Hepburn plays Bunny Watson, the head of an all-female reference division of the company. Bunny and her colleagues are information mavens, able to answer any question spontaneously asked of them or to find the answer almost as quickly. Spencer Tracey plays Richard Sumner, a "methods engineer" or "efficiency engineer," whom Bunny describes as "one of the leading exponents of the electric brain in the country." Shortly after EMERAC is installed in the reference division, it promptly malfunctions, spitting punch cards into the air, emitting smoke, and sounding alarm bells. Still, Bunny saves the day with her human knowledge and her ability to methodically connect information in a sensible order. As the machine spins out of control, Bunny remains cool and knowledgeable. Drawing a parallel to Marcel Duchamp's The Bride Stripped Bare by Her Bachelors, Flanagan describes Bunny as a "metaphoric bride defeating the efficient machines of her bachelor suitor [...]. In the end, Bunny shares her space with the machine yet controls it; she is then enfolded into a new and seemingly more equitable heterosexual relationship" (Flanagan 2004, 154). This is one way the film advances the idea that women's labor and computer labor are complimentary and compatible, rather than at odds.

The film advances this idea by drawing parallels between women's labor and the machine's labor as feminized work. Richard and his female assistant, Ms. Warner, refer to EMERAC as "Emmy," and they personify the machine as a girl. Bunny refers to Ms. Warner as "Ms. Emmy" and EMERAC's mother. EMERAC is seen as temperamental, a longstanding feminine stereotype. The machine is particularly sensitive to dust, smoke, and drafts, such that EMERAC's work space needs to be "scrubbed up," a reference to feminized domestic labor. Yet it is the film's depiction of women's detailed, laborious, and tedious work of finding and organizing data that makes it particularly suitable for automation and that most reflects the assumptions made in IBM's MARC manuals and reports. In just one example from the film, when the president of the corporation invites his all-male executives into the reference division to demonstrate EMERAC's efficiency, Richard explains that "The purpose of this machine is to free the worker of the routine and repetitive tasks and liberate his time for more important work" (italics my own). ${ }^{6}$ Richard further asserts that the labor of managing data is "purely mathematical."

While a number of scholars have explored Desk Set as a primary source in historical studies of information storage and retrieval, many of them do not focus specifically on feminized portrayals of information labor. Colatrella (2001) examines feminized labor in the context of "information sharing," but does not mention the repeated portrayals of the labor as tedious and therefore suitable for automation. Other scholars, some of whom only mention the film in passing, examine various other aspects of the film: the way ordinary citizens perceive computers and their consequences in the 1950s (Anderson 2011, 2013; Cheryl Knott Malone 2002), IBM's effort to recruit women at this time (Abbate 2012), the changing role of the reference librarian in helping to build "user friendly retrieval systems" (LaGuardia 1995, 7), 
feminine labor as an interim step to marriage and family (Colatrella 2001; Flanagan 2004), and the personification of computers as female (Flanagan 2004).

Depicting information labor as repetitive and tedious serves to further reinforce it as a feminized form of labor that lacks intellectual skill. In describing the feminized work of computing during World War II, Light explains,

While college-educated engineers considered the task of computing too tedious for themselves, it was not too tedious for the college-educated women who made up the majority of computers. These were not simply cases of women taking on men's tasks, but rather of the emergence of new job definitions in light of the female workforce. $(1999,461)$

Indeed, women's strengths have long been portrayed as performing repetitive, detailed, methodical, machine-like, systematic, or unintellectual tasks, including labor as typists, librarians, and telephone operators. Evelyn Steele, editorial director of Vocational Guidance Research, writes,

It is generally agreed that women do well at painstaking, tedious work requiring patience and dexterity of the hands. The actual fact that women's fingers are more slender than men's makes a difference. Also, women adapt themselves to repetitive jobs requiring constant alertness, nimble fingers and tireless wrists. They have the ability to work to precise tolerances, can detect variations of ten-thousandths of an inch, [and] can make careful adjustments at high speed with great accuracy. $(1943,46)$

Similarly, The Library Assistants Manual lists the virtues and personal qualities best suited to librarianship, which asks several troublingly sexist questions, including "Has she method and system?," "Is she quick?", and "Are her vibrations pleasant?" (Theodore Koch 1913). In particular, women workers were preferred for the tedious job of cataloging. According to Mary Salome Cutler Fairchild, the unique nature of women qualified them for cataloging work because of their "greater conscientiousness, patience, and accuracy in details" $(1904,162)$. In assessing why women did not hold positions offering high salaries in libraries, Fairchild concluded that women did not have the temperamental fitness to exercise large authority, are not in touch with world affairs, shun responsibility, and lacked originality. In her cultural history of the telephone, Brenda Maddox writes, "The work of successful telephone operating demanded just that particular dexterity, patience and forbearance possessed by the average woman in a degree superior to that of the opposite sex" $(1977,266)$. These portrayals serve to make the sexual division of labor seem natural. By asserting that information retrieval systems must be "as foolproof as the telephone" and "operable by anyone," requiring no special training (Downey 2007, 40), these manuals and reports reinforce this division by referencing women's role as telephone operators and the telephone as an object of feminine domesticity (Maria Lohan 2005). They trivialize women's labor as "tedious," (IBM 1968, 8), "repetitive," (IBM 1964a, 1; 1968, 18), and "clerical" (IBM 1968, 31; Kraft 1966, 1), intellectually incapable of special training or context. It also suggests that justifying the value of this new technology required a managerial justification, instead of a justification by a manufacturer trying to create demand.

Despite these characterizations, working in the MARC system mirrors qualities of computer programming (and later mark-up languages). This is because the cataloger is inputting codes that the computer can read to produce a particular result, in the case of cataloging, for the purpose of display, searchability, or linked data within an online catalog. Whereas cataloging blurs the boundaries between production (programming) and "use" (cataloging systems) that correspond to gendered stereotypes about producers and users of information 
technologies, it is perhaps these persistent presumptions about the natural division of labor that allow the painstaking work of cataloging to be set apart from the painstaking work of computer programming, a field that, as we have seen, was becoming quickly masculinized in the early days of automated information retrieval (Ensmenger 2010), and would continue to grow in power and prestige within librarianship, the university, corporations, and society more broadly throughout the latter part of the twentieth century (Patrick Keilty 2013).

The recent use of XML in catalogs to create Linked Data that will enable semantic queries of catalog records only makes the relationship between cataloging, programming, and mark-up languages more closely related. Cataloging, computer programming, and mark-up languages, while different from each other in significant ways, all share in common the painstaking (some might say "tedious" task) of inserting code and structuring data. They also all require enormous intellectual skill and context in determining how to code or structure data. In the case of cataloging, a cataloger must understand the broader social and cultural context in which an item circulates, the needs and demands of the constituencies who will use it, how those constituencies will use it, and how its use might change over time. The intellectual, cultural, and social contexts of storage, access, and retrieval are at the heart of librarianship. It has given rise to entire subfields within Library and Information Science, a field whose solicitous philosophy of "user-friendly" approaches, cultural constructivism, and social epistemology dates back at least as far as the early days of computation, owing to thinkers such as Suzanne Briet and Jesse Shera (Ron Day 2001).

If understanding the labor of cataloging as merely tedious reveals hidden presumptions about the natural division of labor as well as ignorance about the intellectual skill necessary for cataloging, then it might also explain the techno-utopian presumptions on the part of manufacturers and designers about the way automation would transform that labor.

\section{Shifting labor and expectations}

As we have seen, both popular filmic representations and computer manufacturers' manuals and reports of early library automation assume that modern technology will absolve librarians of the labor of cataloging. It stands to reason, a connection between electronic technology and information labor seems justified: if it takes less time to record metadata electronically than it did with a pencil and typewriter, then cataloging must take less time (and certainly less energy) than it used to, and librarians must therefore have more time for other forms of labor. Nowhere, however, in these various reports and manuals (or in the film Desk Set) is there any consideration of the amount of labor that would be required to manage electronic metadata-to organize, catalog, classify, index, and abstract resources, not to mention formulating queries in the same controlled vocabularies as these-for this vastly expanded global network of accessible and duplicable on-demand multimedia material. ${ }^{7}$ Numerous reports, studies, and manuals comment on the labor-intensive process of retrospective conversion of card catalog data into automated forms, yet little reflection occurs about what cataloging labor looks like after the conversion. Indeed, from Vannevar Bush's "Memex" through the development of early information retrieval systems, little is said about the ways in which new technologies might transform information labor except to assume that it will "lessen the human workload" (Sparks 1962, 1).

We might assume that the decrease in the number of cataloging librarians in the latter part of the twentieth century is evidence in support of the ways in which electronic 
technologies "lessen the human workload" of cataloging. Yet if we consider MARC as a technological system and cataloging as a work process, we see that, in fact, the labor of cataloging has become increasingly diffused and that, ironically, the expectations of cataloging have significantly risen, requiring new kinds of work for the cataloger, not less, requiring new forms of special training, rather than eliminating special training. Whereas Cowan (1983), in her study of feminized labor and domestic technologies, argued that many domestic technologies created more work for women, not less, the impact of automation on library cataloging cannot be understood as a simple binary that understands labor as "less" before automation and "more" after automation. Instead, automation shifted "tedious" labor from analogue systems to automated systems, requiring just as much labor and intellectual skill as before, while increasing the expectations of cataloging labor.

Considering MARC as a technological system means examining it as but one "part in a sequence of implements - a system - in which each part must be linked to others in order to function appropriately" (Cowan 1983, 13). In other words, MARC will not be much good if electric current is missing; without telephone infrastructures; without the creation of the IBM 1401 and IBM 870; without the steel, copper, and aluminum out of which these systems were composed; without the launch of Sputnik; without the Space Race; without the Cold War; without the national economy's shift from manufacturing to communication; and so on. The transformation of cataloging labor had been cast, almost literally, in the non-human sources of electricity, steel, copper, and aluminum from which the technology was composed, as well as the supply lines that keep these materials flowing to us.

Ostensibly, the mechanization of cataloging appears to have been comprised of individual choices freely made by librarians and computer programmers: the Library of Congress developed a program to create a machine-readable cataloging record; librarians throughout the country chose to participate in the MARC Distribution System that established MARC as a professional standard; and so on. But the matter is not as simple as librarians freely deciding to adopt MARC. Broader social, political, and economic interests shaped these choices (Shoshana Zuboff 1988). MARC would not have done librarians a bit of good if IBM had not built the IBM 1401 and IBM 870, and it would not have become as widely distributed without the development of ARPANET, the precursor to the internet, which was simultaneously developed in California. Indeed, the transformation of cataloging labor was part of a long-term investment by the US government as part of the Cold War; and the technological systems and social processes of which it is a part (telephone lines, roads, electricity, computers, ARPANET) were built to last for more than one lifetime.

Considering MARC as a work process, then, means that labor is not a series of "simply defined tasks but is definable tasks that are necessarily linked to one another" (Cowan 1983, 12). This is to ask, as Cowan does, "not only whether one activity has been altered, but also whether the chain in which that activity is a link has been transformed" $(1983,12)$. If we view cataloging as work, then we might reasonably argue that this work can be done faster and with less expenditure of human energy thanks to automation. If, on the other hand, we view cataloging as a work process, then we might see it as composed of several activities: learning to use a computer; typing; learning to input data into MARC; learning cataloging rules in pre-MARC formats; learning to convert cataloging into a MARC format; learning to troubleshoot hardware and software problems; and so on. These are all forms of specialized training, and they're certainly not "foolproof," as the manuals and reports would have us believe. For if a cataloger is unable to troubleshoot a technological problem, then she becomes alienated 
from the tools with which she labors. This is a classic case of new technology in industrialized market labor. If the computer breaks down, the laborer most likely will not know what to do or have the appropriate tools at hand to fix it. In such a scenario, cataloging labor is performed with tools that can neither be manufactured nor understood by the workers who labor with them. Trouble shooting a technological problem is a form of mastery over technology that is often seen as the province of male technology staff. Even as it belies the idea that technology is "foolproof," it nevertheless puts cataloging labor in a passive relation with technology.

Since the rise of automation and conversion to MARC increased the speed at which cataloging occurs (and therefore also increased the expectation of how much cataloging can be done in a set amount of time), and since the conversion to MARC meant fewer professional librarians and an increase in low-paid para-professionals involved in the work (particularly when the creation of metadata is part of a network of labor that gives rise to less "original cataloging" and more "copy cataloging"), then the question of whether cataloging has been made easier or faster by the advent of MARC becomes increasingly more difficult to answer. Easier for whom? Faster for whom? Under what conditions? Even if we can say that more cataloging is done for every hour of work, we can also just as easily say that cataloging after automation and MARC is just as time-consuming and just as demanding as it was before automation and MARC but that the tools with which one labors have changed and the speed with which we expect cataloging to occur has increased.

The automation of library cataloging meant that cataloging labor became increasingly complex, networked, distributed, and heterogeneous. It still required the same intellectual and contextual skills, as well as the same skills of descriptive and analytic metadata, but it also required special training in software programs and troubleshooting. Today, it requires understanding layers of standardization beyond the Anglo-American Cataloging Rules to include the Resource Access Description and standards about the implementation of XML in order to make library catalogs part of the semantic web. The tolls of cataloging have shifted and so has the labor. It is difficult to understand where the labor of cataloging begins and where it ends-what is essential and what is unessential, what is necessary and what is compulsory. If we are doing a time study of catalogers, are we supposed to define the time they spend troubleshooting as work?

\section{Conclusion}

The history of feminized labor cannot be properly understood without the history of the technologies with which it is done-and vice versa. The relation is reciprocal, perhaps even dialectic (Cowan 1983). As Light has previously shown, major wars, including the Cold War, have "unmistakable influences on gender and work, and those effects can be elusive and complex" $(1999,480)$. Against the backdrop of the Cold War, we have seen how feminized labor is tied to technological change. In the case of information retrieval systems, this may be due to the assumption among designers that women's labor is repetitive, tedious, methodical, systematic, machine-like, and, therefore, lends itself easily to automation. In outlining the history of automation, Norbert Wiener describes a similar understanding of systemization and mechanization in Leibnitz's Calculus Ratiocinator, which laid the foundations for machine computation and automata: 
Leibnitz saw in the concordance of the time given by clocks set at the same time, the model for the pre-established harmony of his monads. For the technique embodied in the automata of his time was that of the clockmaker. Let us consider the activity of the little figures which dance on top of the music box. They move in accordance with a pattern, but it is a pattern which is set in advance, and in which the past activity of the figures has practically nothing to do with the pattern of their future activity. The probability that they will diverge from this pattern is nil. There is a message, indeed; but it goes from the machinery of the music box to the figures, and stops there. The figures themselves have no trace of communication with the outer world, except this one-way stage of communication with the pre-established mechanism of the music box. They are blind, deaf, and dumb, and cannot vary their activity in the least from the conventionalized pattern. $(1954,21-22)$

There is little difference between the figures on top of Wiener's music box and the representation of women's work in Desk Set and early IBM manuals. They are both concerned with processes that are portrayed as repetitive, systematic, procedural, and require little contextual and intellectual knowledge. According to this assumption, women's labor embodies the very qualities that have long defined automation.

Designers of automated information retrieval systems, as represented by the character Richard Sumner, wholly believed that automation would "lessen the human workload" and "free the worker of routine and repetitive tasks," with little or no awareness of the ways in which new systems create a shift in expectations and labor. While the automation of cataloging might be seen to have made some aspects of women's work easier, it also appears to have created new forms of labor, shifting it to a new medium, and increasing expectations about how much work can be done in a particular amount of time. Contrary to the manufacturer's and designer's expectations, it also created new forms of special training, rather than eliminating special training. Manufacturers and designers assume that while women perform necessary tasks, their labor was not sufficiently sophisticated to consider the ways in which these new technologies might not only transform their work but their work process. Assumptions that women's work was merely tedious, lacking innovation or intellectual skill, reflects how little designers understood the actual labor involved in data management, and may have led designers to assume that these transformations would have little effect. As a result, designers appear to have been motivated by an uncritical techno-utopian vision of labor and a patronizing form of "feminism" that sought to "free" women of tedious and laborious tasks.

Cataloging continues to be a largely feminized form of labor. The future of MARC remains uncertain. While a granular, complex system, it was designed for outdated technology, and its metadata is rarely transferred outside of library catalogs. Since 2012, the Library of Congress has sought to develop a new standard, BIBFRAME, which will bring cataloging metadata in line with contemporary programming styles and allow the metadata to be more easily reused in various contexts through linked data. The Library of Congress' literature about the BIBFRAME (2016) initiative has little to say about the way this new system will transform the labor of cataloging. Just like the MARC manuals and reports from fifty years earlier, a great deal of attention is paid to implementation but not to long-term shifts in labor. Like MARC, BIBFRAME will require training in new software and learning new standards of bibliographic description while at the same time asking librarians to perform an increasing amount of intellectual and contextual labor about resources by organizing metadata into three core levels of abstraction (work, instance, and item), which are then further organized according to different kinds of relationships (agents, subjects, and events). What this means, 
in its simplest terms, is that librarians will be asked to think conceptually about the relationship between, for example, Jane Austen's Emma, its various translations, the 1995 film Clueless, starring Alicia Silverstone, the subsequent 1996 television show Clueless, and the series of young adult novels published by Simon \& Schuster based on the film, not to mention the seemingly endless list of other transformations of Austen's novel, including the 1996 film, Emma, starring Gwyneth Paltrow, the various BBC television productions (from 1948, 1960,1972 , and 2009), the countless stage productions, and the various companion novels by different authors. The labor of cataloging is more intellectual than ever.

While the move to BIBFRAME and linked data means that information will be much more relational than the current hierarchical structure (think of a web diagram instead of a tree diagram), the use of linked data makes this information not only beneficial to libraries but to anyone within the semantic web. The labor implications are enormous: the tedious work of learning the BIBFRAME system, including a new standard for metadata description and inputting it into software, learning new software and troubleshooting when it fails, learning XML and inputting its codes alongside the description, and making intellectual and contextual choices about the relation between various iterations of an item. Yet the widely held perception that cataloging is merely "tedious" data entry reveals the way in which gendered assumptions about labor survive transitions from manual to automated systems and continue into BIBFRAME, despite the labor of this new system requiring sophisticated intellectual and technical skill. It's a perception that persists even as feminized cataloging work becomes increasingly responsible for the creation of a largely invisible open-source, interoperable data infrastructure that will enable companies such as Google and Amazon, as well as the broader public, to benefit from the meticulous intellectual and contextual work of cataloging for the semantic web.

\section{Notes}

1. The role of the Cold War in creating (at least some of) the infrastructure needed to make a distributed electronic catalog system possible has been well documented in Mark Bowles (2000) and Greg Downey (2007). I leave it to these scholars to trace that history more thoroughly. In this essay, it serves as an occasional backdrop, a nod to the broader context in which library automation developed, but it is not the focus of this paper.

2. One of the National Security Agency's first computer programmers, Henriette Avram, joined the Library of Congress in 1964 to lead the team of people who developed MARC in the Office of Information Systems. Assigned to assess the manipulability of catalog data by computers, Avram and her team quickly devised a standard vehicle for the communication of data, culminating in the MARC Pilot Project. The project yielded a format structure that became the basis of MARC formats worldwide, an extended character set capable of accommodating various diacritics and symbols that became the standard for the Roman alphabet, codes for language and country, and the MARC Distribution Service, a prototype for similar services around the world. By March 1969, the Library of Congress created a subscription service to make MARC available to organizations throughout the country, laying the foundation for WorldCat, a union catalog that, today, itemizes the collections of seventy-two thousand libraries in 170 countries and territories (Online Computer Library Center 2011). For more on Avram's role in the history of MARC see Henriette Avram (2003).

3. It is important to note that librarians at this time were overwhelmingly white, middle-class educated women. According to a study by the US Bureau of Labor Statistics that surveyed librarians in 1970 (published in 1975), 84 percent of librarians were women, 92 percent were white, and between 40 and 50 percent held an advanced degree. The barriers to women of 
color becoming librarians in the 1960s were overwhelming. As Garrison (1979) has shown, many women entered the profession in part because it fit within the parameters of white middle-class notions of femininity. In addition, Gina Schlesselman-Tarango (2016) has shown that white women were deemed an appropriate agent for the racial, missionary, and civilizing projects of early libraries that resulted in the persistence of a particular mode of whiteness within the profession.

4. IBM is the named corporate author on many of these reports. Despite my best efforts, it is impossible to know the names of specific individuals who helped draft reports where only IBM's name appears, with the notable exception of Donald $\mathrm{H}$. Kraft, who is given authorship of four reports relevant to library automation that were published by IBM during this time (1964a, 1964b, 1964c, 1966). As "Industry Representative," Kraft marketed computer applications to libraries on IBM's behalf. Kraft started his staff position in the company's Chicago office in 1961 , initially selling punch-card equipment to libraries, which libraries used to print purchase orders, catalog cards, and labels for book spines and pockets, as well as some accounting and payroll functions. By 1964, with the development of Machine-Readable Cataloging (MARC), IBM marketed its equipment to libraries that wished to convert their catalogs to the new electronic system. Kraft represented IBM in the mid-west and western United States. In an email correspondence, Kraft did not explain why his name appears on some reports and not others or who else might have been responsible for writing these reports. His most immediate supervisor at this time was Steve Furth, who worked closely with Hans Peter Luhn, a pioneer of information retrieval at IBM, whose inventions served as a catalyst for library automation. For more on Luhn, see Claire K. Schultz (1968).

5. This list represents only a small sample of the many reports and manuals that use this language in describing cataloging labor. Space limitations prevent me from citing every example from every report and manual. Instead, I highlight some of the most relevant examples for library automation.

6. Despite Richard's use of the male pronoun, there is no doubt that "the worker" to which he refers is a woman, specifically the women working in the company's reference division.

7. Some readers might conceive of MARC as a mere data format that enabled automation. However, Jeffrey Schnapp and Matthew Battles argue that, in fact, MARC is an entire technoinfrastructure that enables books to be born as data objects, networks unto themselves, which circulate in advance of their appearance as a bound volume $(2014,18)$. As a result, it is difficult to disentangle MARC from the technological system of which it is a part or from the cataloging labor that these systems transformed and enabled.

\section{Disclosure statement}

No potential conflict of interest was reported by the author.

\section{Notes on contributor}

Patrick Keilty is Assistant Professor in the Faculty of Information at the University of Toronto. He works at the intersection of media studies, technology studies, and information studies. His primary teaching and research field is digital studies, with a particular focus on visual culture, pornography, metadata and database logic, database cinema, critical theory, and theories of gender, sexuality, and race. E-mail: p.keilty@utoronto.ca

\section{References}

Abbate, Janet. 2003. "Women and Gender in the History of Computing." IEEE Annals of the History of Computing 24 (2): 4-8. 
Abbate, Janet. 2012. Recording Gender: Women's Changing Participation in Computing. Cambridge, MA: MIT Press.

Anderson, Steve F. 2011. Technologies of History: Visual Media and the Eccentricity of the Past. Dartmouth, $\mathrm{NH}$ : Dartmouth College Press.

Anderson, Steve F. 2013. "Chaos and Control: The Critique of Computation in American Commercial Media, 1950-1980." American Literature 85(4). Accessed August 12, 2014. http://scalar.usc.edu/anvc/ chaosandcontrol/index

Avram, Henriette. 2003. "Machine-Readable Cataloging Program." In Encyclopedia of Library and Information Science, edited by Miriam Drake, 1712-1730. New York: Marcel Dekker.

BIBFRAME. 2016. "Bibliographic Framework Initiative." Accessed July 6, 2016. https://www.loc.gov/ bibframe/

Bowles, Mark. 2000. "Liquifying Information: Controlling the Flood in the Cold War and beyond." In Cultures of Control, edited by Miriam R. Levin, 225-246. Amsterdam: Harwood Academic.

Bush, Vannevar. 1945. "As We May Think." The Atlantic July, 101-108.

Colatrella, Carol. 2001. “From Desk Set to the Net: Women and Computing Technology in Hollywood Films." Canadian Review of American Studies 31 (2): 1-14.

Cowan, Ruth Schwartz. 1983. More Work for Mother: The Ironies of Household Technology from the Open Hearth to the Microwave. New York: Basic Books.

Day, Ron. 2001. The Modern Invention of Information: Discourse, History, and Power. Carbondale: Southern Illinois University Press.

Desk Set. 1957. Directed by Walter Lang. Beverly Hills, CA: Twentieth Century Fox Corporation. DVD.

Downey, Greg. 2007. "The Librarian and the Univac: Automation and the Labor at the 1962 Seattle World's Fair." In Knowledge Workers in the Information Age, edited by Catherine McKercher and Vincent Mosco, 37-52. Lantham: Lexington Books.

Ensmenger, Nathan. 2010. The Computer Boys Take over: Computers, Programmers, and the Politics of Technical Expertise. Cambridge, MA: MIT Press.

Epstein, Cynthia F. 1971. Women's Place: Options and Limits in Professional Careers. Berkeley: University of California Press.

Fairchild, Mary Salome Cutler. 1904. "Women in American Libraries." Library Journal 29: 157-162.

Flanagan, Mary. 2004. "The Bride Stripped Bare to Her Data: Information Flow + Digibodies." In Data Made Flesh: Embodying Information, edited by Robert Mitchell and Phillip Thurtle, 153-180. New York: Routledge.

Futura, Kenneth. 1990. "The Impact of Automation on Professional Catalogers." Information Technology in Libraries 9 (3): 242-252.

Garrison, Dee. 1979. Apostles of Culture: The Public Librarian and American Society, 1876-1920. New York: The Free Press.

IBM. 1960. IBM Circulation Control at Brooklyn College Library. White Plains, NY: IBM, Data Processing Division.

IBM. 1963a. General Information Manual: Mechanized Library Procedures. White Plains, NY: IBM, Data Processing Division.

IBM. 1963b. The IBM 870 Library Administrative Processing System for Federal Government Library and Special Information Repositories. White Plains, NY: IBM, Data Processing.

IBM. 1964a. Library Catalog Production-1401 and 870. White Plains, NY: IBM, Technical Publications Department.

IBM. 1964b. A System for Library Card Production. White Plains, NY: IBM, Data Processing.

IBM. 1968. Online Library Circulation Control System. White Plains, NY: IBM.

Keilty, Patrick. 2013. "Introduction." In Feminist and Queer Information Studies Reader, edited by Patrick Keilty and Rebecca Dean, 1-9. Sacramento, CA: Litwin Books.

Koch, Theodore. 1913. The Library Assistants Manual. Lansing, MI: State Board of Library Commissioners. Accessed August 19, 2014. http://www.gutenberg.org/files/46555/46555-h/46555-h.htm

Kraft, Donald H. 1964a. Applications of IBM Equipment to Library Mechanization. Chicago, IL: IBM.

Kraft, Donald H. 1964b. IBM Library Circulation Systems. Chicago, IL: IBM.

Kraft, Donald H. 1964c. A Total Systems Approach to Library Mechanization. White Plains, NY: IBM. 
Kraft, Donald H. 1966. A Total Systems Approach to Library Automation with Data Processing Equipment. Chicago, IL: IBM.

LaGuardia, Cheryl. 1995. "Desk Set Revisited: Reference Librarians, Reality, \& Research Systems' Design.” Journal of Academic Librarianship 21 (1): 7-9.

Light, Jennifer. 1999. “When Computers Were Women.” Technology and Culture 40 (3): 455-483.

Lohan, Maria. 2005. "Men, Masculinities, and 'Mundane' Technologies: The Domestic Telephone." In Virtual Gender: Technology, Consumption, and Identity Matters, edited by Allison Adam and Eileen Green, 189-206. New York: Routledge.

Maddox, Brenda. 1977. "Women and the Switchboard." In The Social Impact of the Telephone, edited by Ithiel de Sola Pool, 262-280. Cambridge, MA: MIT Press.

Malone, Cheryl Knott. 2002. "Imagining Information Retrieval in the Library: Desk Set in Historical Context." IEEE Annals in the History of Computing 24 (2): 14-22.

New York Times.1961. "Library of the Future." December 15.

Online Computer Library Center. 2011. “OCLC Board of Trustees to Engage Members in Process to Select Next CEO and President." Accessed July 6, 2016. http://www.oclc.org/news/releases/2011/201145. en.html

President's Science Advisory Committee. 1958. Strengthening American Science: A Report of the President's Science Advisory Committee. Washington, DC: U.S. Government Printing Office.

Pugh, E. W. 1995. Building IBM. Cambridge, MA: MIT Press.

Rayward, Boyd. 2002. "A History of Computer Applications in Libraries." IEEE Annals of the History of Computing 24 (2): 4-15.

Schiller, Dan. 2007. How to Think about Information. Urbana: University of Illinois Press.

Schlesselman-Tarango, Gina. 2016. "The Legacy of Lady Bountiful: White Women in the Library." Library Trends 65 (1): 667-686.

Schnapp, Jeffrey, and Matthew Battles. 2014. The Library beyond the Book. Cambridge, MA: Harvard University Press.

Schultz, Claire K. 1968. H. P. Luhn: Pioneer of Information Science. New York: Spartan Books.

Sparks, David E. 1962. A Machine Interpretable Format for Library Cataloging. Lexington, MA: Itek Corporation.

Steele, Evelyn. 1943. Wartime Opportunities for Women. New York: E. P. Dutton.

U.S. Bureau of Labor Statistics. 1975. Library Manpower: A Study of Demand and Supply. Washington, DC: The Bureau.

Wajcman, Judy. 1991. Feminism Confronts Technology. University Park: University of Pennsylvania Press.

Wiegand, Wayne A. 1999. "Tunnel Vision and Blind Spots: What the Past Tells Us about the Present: Reflections on the Twentieth-Century of American Librarianship." The Library Quarterly 69 (1): 1-32.

Wiener, Norbert. 1954. The Human Use of Human Beings: Cybernetics and Society. Boston, MA: Da Capo Press.

Zuboff, Shoshana. 1988. In the Age of the Smart Machine: The Future of Work and Power. New York: Basic Books. 